\title{
Toward A Renewed Sociology of Mass Media and Popular Culture
}

\author{
Lawrence T. Nichols
}

Published online: 11 September 2009

(C) Springer Science + Business Media, LLC 2009

In this issue we present a set of papers that examine sociology's engagement with the study of mass media, communications and popular culture, from the perspective of historical efforts as well as possible future directions. The picture that emerges from the individual articles is rather paradoxical, for it appears that the fields of media and popular culture have been both mainstream and marginal within the discipline. The paradox is perhaps partly explainable in terms of shifts in what Don Levine has called "visions of the sociological tradition." Thus, for several decades, the field was largely framed as "the science of institutions," with emphasis on conflict, adaptation and survival (in both Durkheimian and Social Darwinist variants). Within such a perspective, a focus on media and popular culture is not highly valued, not taught in graduate programs, and not highly rewarded as a career path. In the same way, a dominant emphasis on sociology as "the science of inequality," with particular attention to race, gender, class and sexual orientation, tends to discourage work on media and culture except insofar as it might deal with the overarching issues of power and differential victimization.

Now, as sociologists think of themselves more and more within a "postmodern" framing that approaches "society as text" and embraces a "narrative turn," the subjects of mass media, communications and popular culture take on a new relevance. The recent movement toward a "public sociology" also reinforces the shift, as sociologists become increasingly concerned about the image of the discipline in the popular imagination, and about the most effective means of engaging publics and conveying sociological messages with policy implications.

Ronald Jacobs begins our discussion with an examination of the work of Robert Park in the 1920s, which he believes can help sociology regain a proper focus on "culture and the public sphere." He approaches Park's writings in terms of two organizing themes: (1) news and the power of the press; and (2) diverse cultural forms of newspaper discourse. Jacobs concludes that renewed attention to Park, 
considered as a "classical founder," will also help media studies attain greater legitimation within the field.

Elihu Katz offers thoughtful reflections on the troubling issue of why sociology abandoned communication research. He examines a series of possible explanatory factors, including the attitude of Paul Lazarsfeld and the Bureau of Applied Social Research at Columbia, the association of communications research with the communitarian perspective, and the lack of interest among sociologists in "event analysis." The combined effect of these and other related factors, Katz suggests, has been to marginalize communications research in sociology within the catch-all category of "collective behavior."

Rodney Benson continues the discussion of the public sphere through a careful analysis of the work of Jurgen Habermas. In Benson's view, the writings of Habermas provide a potentially valuable starting point for a revitalized and expanded sociology of mass media. At the same time, however, he argues for the need to move beyond the Habermas model toward an approach that would also draw upon Bourdieu's field theory and the new institutionalism for purposes of a democratic reformist agenda.

John Conklin's paper shifts the focus from mass media to cultural products, especially commercially produced films. His particular interest is in images of sociology that have appeared in cinema from the early twentieth through the early twenty-first centuries. Conklin finds that Hollywood's overall picture of sociologists, not surprisingly, tends to emphasize negative stereotypes, though it also acknowledges legitimate expertise. He suggests that future researchers try to elucidate the origins of film makers' ideas about the discipline, and also the effects on the field of these pop culture representations.

Peter Behrens returns to the issue of mass media, but his paper broadens our perspective by examining the case of the neighboring field of psychology. He shows how early psychological entrepreneurs utilized the new medium of radio to popularize their discipline, especially by framing their efforts as "public service" that offered education and adjustment through such regular programs as "Parents Talk," "Women's Radio Review" and "Psychology at Work," as well as special features on "Vocational Guidance" and the contemporary controversy over spiritualism. The historical case of psychology may prove instructive for all who are interested in building a public sociology that resonates with audiences in the twenty-first century.

The final paper, by Peter Beilharz, expands our perspective once more, this time by focusing on the sociology of popular culture in Australia and New Zealand. Beilharz is especially concerned with the attitude or stance toward the study of culture that he believes arises out of the position of the Antipodes in the larger world system. He seeks to trace the reciprocal movement of culture from center to periphery, and back, and concludes with reflections about practicing sociology in smaller places that are rich in interdisciplinary collaboration. 